\section{Commentary: Congenital aortic arch reconstruction: Keeping the window open}

\author{
Harold M. Burkhart, MD, ${ }^{\mathrm{a}}$ Arshid Mir, MD, ${ }^{\mathrm{b}}$ and \\ Yuki Nakamura, MD
}

Patients with single-ventricle anatomy such as hypoplastic left heart syndrome, tricuspid atresia with transposition, and double-inlet left ventricle with subaortic stenosis who need a Norwood-type arch augmentation are at risk of bronchial or left pulmonary artery compression. ${ }^{1}$ The common issue in most of these patients is either compression in the anteroposterior plane due to a narrow interaortic distance (aortic width) between the reconstructed ascending aorta and descending aorta secondary to an enlarged DamusKaye-Stansel (DKS) anastomosis or superior-inferior compression because of a Gothic configuration of the reconstructed arch resulting in decreased height. ${ }^{2}$ In tricuspid atresia with tricuspid atresia with transposition and doubleinlet left ventricle, where the native ascending aorta is not diminutive, most patients after repair tend to have an enlarged DKS anastomosis reducing the aortopulmonary window, putting the left pulmonary artery and left bronchus at risk of compression. In hypoplastic left heart syndrome, the decreased aortopulmonary space may be due to an enlarged DKS secondary to too much patch material, using no patch at the time of Norwood reconstruction, or neoaortic root dilation. The true incidence of bronchial compression is unknown, since routine cross-sectional imaging is not always obtained in these patients. However,

From the ${ }^{\mathrm{a} D i v i s i o n}$ of Cardiovascular and Thoracic Surgery, and ${ }^{\mathrm{b}}$ Section of Pediatric Cardiology, University of Oklahoma Health Sciences Center, Oklahoma City, Okla.

Disclosures: The authors reported no conflicts of interest.

The Journal policy requires editors and reviewers to disclose conflicts of interest and to decline handling or reviewing manuscripts for which they may have a conflict of interest. The editors and reviewers of this article have no conflicts of interest.

Received for publication May 17, 2021; revisions received May 17, 2021; accepted for publication June 1, 2021; available ahead of print June 15, 2021.

Address for reprints: Harold M. Burkhart, MD, Division of Cardiovascular and Thoracic Surgery, University of Oklahoma Health Sciences Center, P.O. Box 26901, WP-2230, Oklahoma City, OK 73105 (E-mail: Harold-burkhart@ouhsc. edu).

JTCVS Techniques 2021;8:132-4

2666-2507

Copyright (c) 2021 The Author(s). Published by Elsevier Inc. on behalf of The American Association for Thoracic Surgery. This is an open access article under the CC BY-NC-ND license (http://creativecommons.org/licenses/by-nc-nd/4.0/).

https://doi.org/10.1016/j.xjtc.2021.06.006

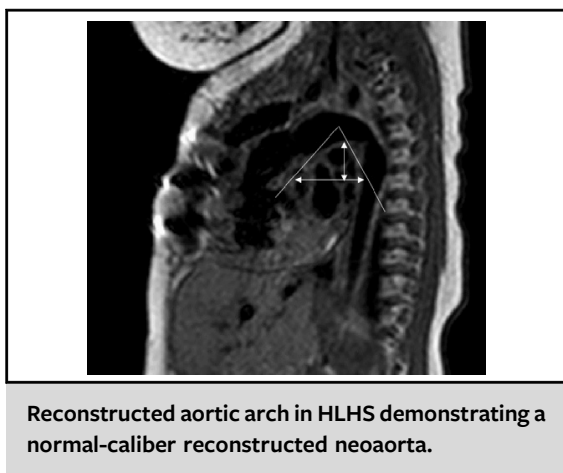

CENTRAL MESSAGE

Aortic arch reconstruction resulting in decreased aortopulmonary space presents a complex surgical challenge.

the incidence is likely greater than known because most patients with mild-to-moderate bronchial compression do not have significant symptoms, prompting further testing.

In this issue of the JTCVS Techniques, Chiu and colleagues $^{3}$ describe an innovative approach to a 19-yearold patient with left bronchial compression secondary to decreased aortic arch height after Norwood reconstruction. The repair involved descending aortic elongation with an interposition graft via left thoracotomy using left heart bypass. In addition, they used a commercially available resorbable implant for the external stenting of the left bronchus. Overall, the successful procedure resulted in opening the aortopulmonary window and providing symptomatic relief. Advantages to this approach over a median sternotomy include the avoidance of a redo median sternotomy and hypothermic circulatory arrest. Disadvantages include graft concerns (need for reintervention, risk of kinking), increased risk to recurrent laryngeal nerve injury due to the need for extensive arch mobilization, and the inability to address a left pulmonary artery issue.

Other approaches to augmenting the aortopulmonary window have been reported. Baker and colleagues described their experience with 7 patients (aged 7 months to 7 years) who underwent ascending aortic extension with a polytetrafluoroethylene interposition graft to augment the aortopulmonary widow and alleviate pulmonary artery stenosis. Six of these patients needed hypothermic circulatory arrest, and there was 1 postoperative death secondary to fungal sepsis. At intermediate follow-up, there 


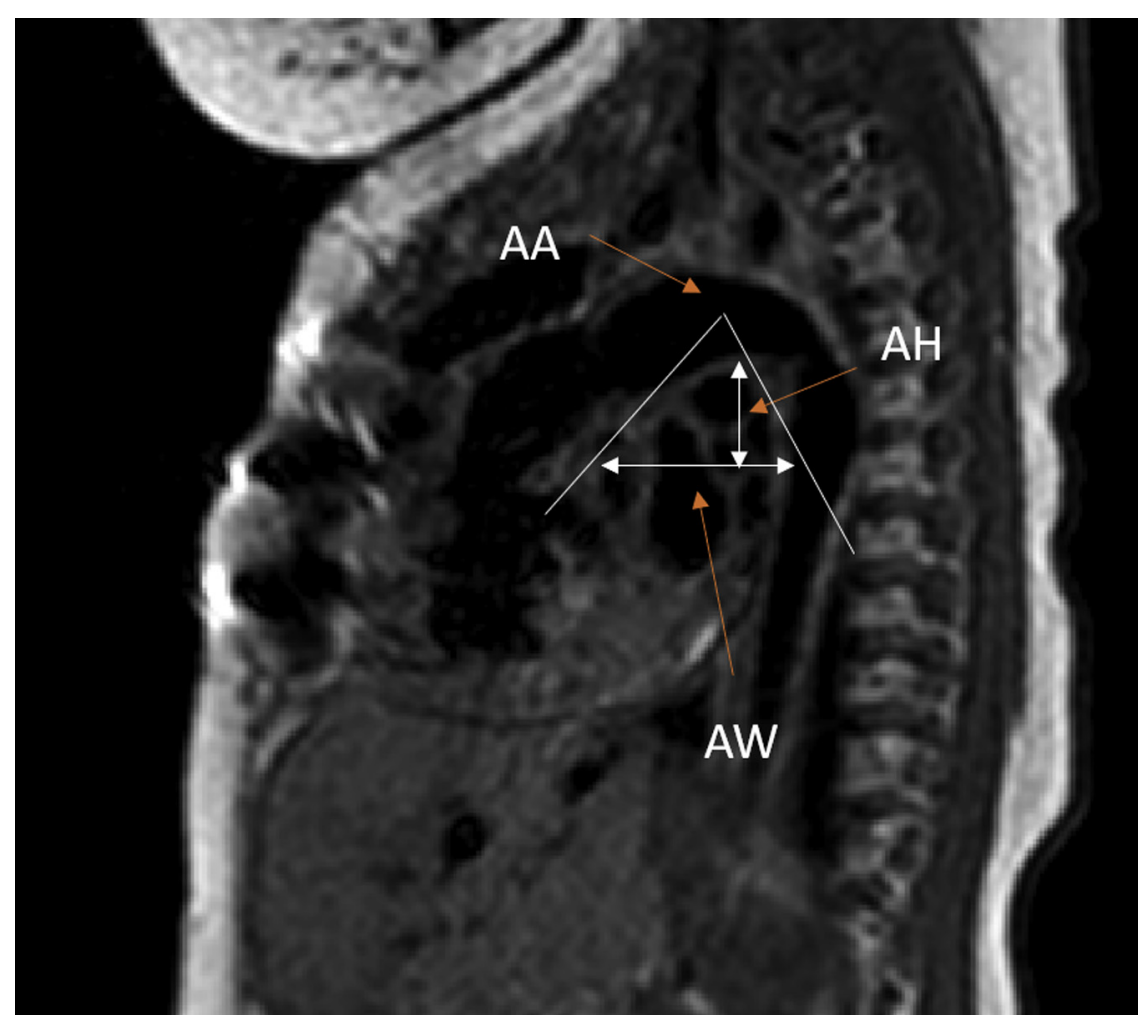

FIGURE 1. Magnetic resonance imaging of a reconstructed aortic arch in hypoplastic left heart syndrome demonstrating a normal caliber reconstructed neoaorta with normal aortic width and normal height of the arch. $A A$, Aortic arch angle; $A H$, arch height; $A W$, arch width.

was unobstructed aortic and pulmonary artery flow. Arcieri and colleagues ${ }^{4}$ reported their experience 18 patients (age 0.3-15.4 years) with left mainstem bronchus compression. All underwent a left thoracotomy with extensive descending aortic mobilization with anchorage to the thoracic vertebral fascia. At follow-up, the majority (17/18) demonstrated adequate airway patency. We have used both of these techniques, depending on the pathology and the need for pulmonary artery intervention, with good results.

Another approach is insuring adequate space in the window at the initial aortic arch surgery. Aortic arch reconstruction in single-ventricle patients has the potential to cause distortion and narrowing of the aortopulmonary space. This deformation can result in extrinsic compression of the bronchus and/or branch pulmonary artery by the neoaorta. Typically, the neoaortic arch after Norwood reconstruction has a smaller angle, is lower in height, and is narrower. The 3 factors when reconstructing the arch in these patients is arch angle (angle between the highest point of the aortic arch to the centerline of the aortic arch), arch height (the inferior margin of arch to the left main bronchus), and arch width (the posterior margin of the ascending aorta to the anterior margin of the descending aorta at the level of the bronchus) (Figure 1). ${ }^{5}$ The focus during initial arch surgery should be to use a smaller patch to reconstruct the aorta with maintenance of arch angle augmentation to create adequate aortopulmonary space. The goals should be creation of a neoaorta that has a larger angle, is taller, and has a wider neoaortic arch. With these modifications, the aim is to create an arch that is more Romanesque in shape and avoid a Gothic configuration. Hopefully using these adjustments would decrease the incidence of pulmonary artery and bronchial compression within the aortopulmonary window.

In conclusion, the current report serves to remind us of the complex nature of the aortic arch reconstruction in single-ventricle patients and the morbidity associated with an inadequate aortopulmonary window. They provide a novel surgical approach that will prove useful in select patients. In addition, we should remember being proactive at the time of initial aortic arch reconstruction will likely impact the incidence of these long-term morbidities by keeping the window open.

\section{References}

1. Baker CJ, Wells WJ, Derby CA, Rizi S, Starnes VA. Ascending aortic extension for enlargement of the aortopulmonary space in children with pulmonary artery stenosis. Ann Thorac Surg. 2005;80:1647-51.

2. Menon A, Jones T, Barron D, Stumper O, Brawn W. Posterior reduction aortoplasty for left pulmonary artery compression after Norwood procedure. Ann Thorac Surg. 2011;91:1300-1.

3. Chiu P, Jennings RW, Marx G, Baird CW. Aortic elongation and bronchial splint for late bronchial complication after neonatal arch reconstruction. J Thorac Cardiovasc Surg Tech. 2021;8:126-8. 
4. Arcieri L, Serio P, Nenna R, Di Maurizio M, Baggi R, Assanta N, et al. The role of posterior aotopexy in the treatment of left mainstem bronchus compression. Interact Cardiovasc Thorac Surg. 2016;23:699-704.
5. Hasegawa T, Oshima Y, Maruo A, Matsuhisa H, Tanaka A, Noda R, et al. Aortic arch geometry after the Norwood procedure: the value of arch angle augmentation. J Thorac Cardiovasc Surg. 2015;150:358-66. 